\title{
Measuring Satisfaction in Breast Cancer Patients Receiving Ambulatory Care: A Validation Study
}

\author{
Tabassum Wadasadawala ${ }^{1}$ Akshay Mangaj ${ }^{2}$ Smruti Mokal ${ }^{3}$ Rima Pathak ${ }^{2}$ Rajiv Sarin ${ }^{2}$ \\ Mithila Gaikar ${ }^{3}$ Nita Nair ${ }^{4}$ Jyoti Bajpai ${ }^{5}$ Shalaka Joshi ${ }^{4}$ Seema Gulia ${ }^{5}$
}

\footnotetext{
1 Department of Radiation Oncology, ACTREC, Tata Memorial Centre, Homi Bhabha National Institute, Navi Mumbai, Maharashtra, India

2 Department of Radiation Oncology, Tata Memorial Hospital, Homi Bhabha National Institute, Mumbai, Maharashtra, India

3 Department of Clinical Research, Tata Memorial Hospital, Homi Bhabha National Institute, Mumbai, Maharashtra, India

${ }^{4}$ Department of Surgical Oncology, Tata Memorial Hospital, Homi Bhabha National Institute, Mumbai, Maharashtra, India

${ }^{5}$ Department of Medical Oncology, Tata Memorial Hospital, Homi Bhabha National Institute, Mumbai, Maharashtra, India
}

Address for correspondence Tabassum Wadasadawala, MD, DNB, Department of Radiation Oncology, ACTREC, Tata Memorial Centre, Homi Bhabha National Institute, Kharghar, Navi Mumbai, Maharashtra 410210, India (e-mail: drtabassum2004@rediffmail.com).

Ind J Med Paediatr Oncol 2022;43:473-479.

\begin{abstract}
Keywords

- breast cancer

- outpatient

- patient satisfaction

- satisfaction survey
\end{abstract}

Introduction Patient satisfaction constitutes a vital service quality indicator. It provides a measure of the gap in health-care requirements and patients' expectations. Objective The aim of this study was to perform linguistic validation of the questionnaire assessing satisfaction with outpatient care.

Materials and Methods A tool for measuring patient satisfaction was developed and validated at our institute in the English language. This tool was translated into Hindi and Marathi. Subsequently, 339 patients diagnosed with breast cancer consulting in the outpatient department from the different parts of India and having diverse linguistic and socioeconomic backgrounds were enrolled. Patients were asked to complete the satisfaction tool after consultation at a single point of time in a prospective manner. Results All patients completed the questionnaire. The questionnaire was filled by 120, 116, and 103 patients in Hindi, Marathi, and English, respectively. Both convergent validity and discriminant validity were supported as the correlation coefficient was $>0.4$ for all items within a scale and $<0.7$ between different scales. Factor analysis was valid for all except for open-end questions. The internal consistency was $>0.9$ for all the questions. The mean overall satisfaction score was 88.35 (standard deviation: 19.63). Patients were satisfied in all the aspects of the consultation process, including appointment scheduling, assistant medical staff and faculty, and treating physician. However, some expressed dissatisfaction toward long-waiting times.

Conclusion The translated tool is reliable and valid and effectively measures the satisfaction of patients receiving ambulatory care. received

May 23, 2020

accepted after revision

August 6, 2020
DOI https://doi.org/

10.1055/s-0041-1735601. ISSN 0971-5851. (c) 2022. The Author(s).

This is an open access article published by Thieme under the terms of the Creative Commons Attribution License, permitting unrestricted use, distribution, and reproduction so long as the original work is properly cited. (https://creativecommons.org/licenses/by/4.0/)

Thieme Medical and Scientific Publishers Pvt. Ltd., A-12, 2nd Floor, Sector 2, Noida-201301 UP, India 


\section{Introduction}

Nowadays, a lot of attention is paid toward the patient's perception of the services provided, especially in oncology. Patient satisfaction measures the gap in the quality of service delivered and patients' expectations. ${ }^{1}$ There are various definitions of patient satisfaction. ${ }^{1-12}$ It measures the patient's contentment with health-care services. ${ }^{13}$ Heath states that a truly satisfied patient can be recognized if he leaves the physician's clinic with a happy feeling. ${ }^{14}$ Assessment of satisfaction levels provides a patient-centered dimension of assessing health systems. ${ }^{15}$ It is important to assess patient satisfaction with the services at multiple levels as medical care is provided by a team of physicians, nurse, and other ancillary staff. It also forms a vital measure of quality tracking and is usually employed by the hospital administrators as a performance indicator. ${ }^{16}$

While there are numerous methods of evaluating patient satisfaction, satisfaction surveys are widely employed because they are easier to perform. There are numerous validated surveys available to measure patient satisfaction like the European Organization for Research and Treatment of Cancer inpatient and outpatient satisfaction questionnaire (EORTC QLQ-OUTPATSAT35, INPATSAT 32), ${ }^{17,18}$ Patient Satisfaction and Quality in Oncological Care, ${ }^{19}$ Long form Patient Satisfaction Questionnaire (PSQ-III), ${ }^{20}$ and Princess Margaret Hospital Satisfaction with Doctor Questionnaire (PMH-PSQ-MD) ${ }^{21}$ are a few of them. They are developed to test the satisfaction of inpatients and also have restricted questions for differential evaluation of various members of the medical team (resident, physician, or nurse). As the needs of developing nations are far different from a developed nation, ${ }^{22,23}$ these above questionnaires need to be validated in the Indian setting. Unfortunately, none of these tools were found to be validated in the Indian population till the time of reporting of this study. Hence, we decided to develop an indigenous questionnaire that will be suitable for the Indian population and can be used in an outpatient department (OPD). It was developed in the English language in phase I and pilot tested in 50 patients who were fluent in English and attending the outpatient breast clinic at our institute. ${ }^{24}$ This tool was subsequently translated in local languages, that is, Hindi and Marathi. In this study, we intend to perform linguistic validation of the tool in patients with varied linguistic and socioeconomic background as well as test the validity and reliability of this translated questionnaire in a larger cohort of patients.

\section{Materials and Methods}

The development process and the initial pilot testing of the patient satisfaction survey (PSS) questionnaire have been published earlier. ${ }^{24}$ The results of pilot testing supported convergent validity showing high internal consistency and high reliability. The PSS tool consisted of 28 questions; six questions related to administrative services; one question on waiting time; eight questions on ancillary members of the medical team comprising of resident doctors, nurses, and other staff; and ten questions about the treating consultant. The participants could choose any one of the options on a numerical scale of 1 (very dissatisfied) to 5 (very satisfied) depending upon their experience after OPD consultations. The last three questions were open-ended, and the responses were to be scored as Yes or No. The respondents at the end had to rate their overall satisfaction on the same scale ranging from 1 to 5 . Our previous publication describes the details of scoring and conversion of raw scores to final scores that were used for the analysis. The initial tool was developed only in the English language; further, the tool was translated into Hindi and Marathi language each by two independent translators. The draft Hindi and Marathi tools were backtranslated by two different independent translators, and a final tool was generated. These final versions of Hindi and Marathi tools along with the English tool were served to the patients as per their preferred language at their first consultation in a prospective manner. Patients from all over India with different socioeconomic backgrounds who were diagnosed with breast cancer and attending outpatient clinics for consultation in our hospital were screened and consequently enrolled. Patients with metastatic disease and poor performance status were excluded from the study.

Patients who had histologically confirmed the diagnosis of breast cancer, planned to receive multimodality cancerdirected therapy (surgery, chemotherapy, and radiation therapy) and who were able to understand either of the three languages were screened for the study and consented. Unfit patients with poor performance status and those unable to read and comprehend the questionnaire were excluded.

To reduce bias, the translated tool was served after the patient had OPD consultation by a clinical research staff not involved in patient care. Patients were asked to fill the tool waiting in the clinic area, and it was anonymous. Three hundred and thirty-nine patients diagnosed with breast cancer consulting in an outpatient clinic in our hospital were enrolled.

\section{Statistical Analysis}

The analysis was done using the Statistical Package for the Social Sciences software version 23.0. A pilot study conducted in Tata Memorial Hospital with the PSS questionnaire has shown that $\sim 70 \%$ of the patients are satisfied with the health-care services. Assuming that the proportion of patients satisfied with the health services, when assessed by Hindi and Marathi PSS questionnaire, would be $\pm 5 \%$ of $70 \%$ (between $65 \%$ to $75 \%$ ), a sample size of 340 would be needed to produce a two-sided $95 \%$ confidence interval $(\mathrm{CI})$, which was determined by using CIs Formula-ClopperPearson method. Data were summarized using the standard measures of central tendency based on the normality distribution of the variables. The item scale and scale-scale correlations were studied for measuring the discriminant and convergent validity. Convergent validity was performed by using the Spearman rank correlation. If individual items within a scale showed moderate or high correlation within their scale $(>0.40)$ convergent validity would be proven. For 
discriminant validity, to indicate that the two scales are different in construct, scale to scale correlation coefficient of $\leq 0.70$ was required. Discriminant validity for each item was tested by counting the number of times that the item correlated higher with items of other domains than with items of its own domain. Campbell and Fiske suggest that the count should be $<1 \frac{11 / 2}{2}$ the potential comparisons. ${ }^{25}$ The Kaiser-Meyer-Olkin (KMO), ${ }^{26}$ a measure of sampling adequacy and Bartlett's test of Sphericity, ${ }^{27}$ which are standard tools for exploratory factor analysis, were used for inferring construct validity. A value of KMO $\geq 0.5$ and $p \leq 0.05$ for Bartlett's test is supposed to support construct validity. Similarly, internal consistency and reliability of the questionnaire were assessed by Cronbach's $\alpha$ coefficient. A value of Cronbach's $\alpha$ coefficient $\geq 0.70$ supports internal consistency.

\section{Results}

All 339 female patients who gave consent for the study responded to the entire questionnaire that showed a high compliance of $100 \%$. The demographic details of the study cohort are shown in -Table 1. The paid and subsidized categories were equally distributed. Majority of the patients were literate $314(94.6 \%)$, homemakers 261 (77.0\%), and had good family support 310 (91.4\%). Local patients comprised $20 \%$ of the entire cohort. The questionnaire was filled in Hindi, Marathi, and English by 120, 116, and 103 patients, respectively.

\section{Convergent Validity}

The interitem correlation for items (1-6) under appointments and secretarial assistance ranged from 0.62 to 0.78 ; $p<0.001$; for assisting medical staff and facilities (items: 9 16 ), the interitem correlation ranged between 0.7 and 0.85 ; $p \leq 0.001$. For items (17-26) that assessed the satisfaction related to treating physician (consultant), the interitem correlation ranged from 0.67 to $0.86 ; p<0.001$. Since all the items have correlation $>0.4$, convergent validity was supported (-Table 2 ).

\section{Discriminant Validity}

- Table 2 describes the result of discriminant validity in detail. In this analysis, potential correlations are studied between each item of one domain with the items of other domains. The correlation coefficient is recorded for all comparisons. The result of comparisons is recorded as a violation
Table 1 The demographic profile of the patients

\begin{tabular}{|c|c|}
\hline Characteristics & Numbers (percentages) \\
\hline Age & $\begin{array}{l}\text { Median } 49 \text { years } \\
\text { (range: } 25-80 \text { years) }\end{array}$ \\
\hline \multirow[t]{3}{*}{ Stage (\%) } & Stage I-38 (11.2) \\
\hline & Stage II-88 (26.1) \\
\hline & Stage III-213 (62.7) \\
\hline \multirow[t]{3}{*}{ Laterality (\%) } & Left-180 (53.0) \\
\hline & Right-156 (46.1) \\
\hline & Bilateral-3 (0.9) \\
\hline \multirow[t]{2}{*}{ Category (\%) } & Fully paid-172 (50.7) \\
\hline & Subsidized-167 (49.3) \\
\hline \multirow{2}{*}{$\begin{array}{l}\text { Family/social } \\
\text { support (\%) }\end{array}$} & Yes-310 (91.4) \\
\hline & No-29 (8.6) \\
\hline \multirow[t]{6}{*}{ Education level (\%) } & $\mathrm{Nil}-12(3.5)$ \\
\hline & Primary-66 (19.5) \\
\hline & Secondary-92 (27.1) \\
\hline & Graduate-151 (44.5) \\
\hline & Postgraduate-5 (1.5) \\
\hline & Not mentioned-13 (3.8) \\
\hline \multirow[t]{5}{*}{ Occupation (\%) } & Homemaker-261 (77) \\
\hline & Student-1 (0.3) \\
\hline & Employed-61 (18) \\
\hline & Retired-7 (2.1) \\
\hline & Not mentioned-3 (0.9) \\
\hline \multirow[t]{2}{*}{ Place of residence (\%) } & Mumbai-81 (20.3) \\
\hline & Outside Mumbai-258 (79.7) \\
\hline
\end{tabular}

if the correlation coefficient is $>0.7$. If such violations are $<50 \%$, then it is concluded that the discriminant validity is supported. For items (1-6) under appointment and secretarial assistance, of the 108 potential comparisons, there were no violations. Similarly, for items (9-16) under assisting medical staff and facilities, there was only one violation out of 128 comparisons. For items (17-26) under treating physician (consultant), also there was one only violation out of 140 comparisons. As shown in - Table 2, as all the values for scale-scale correlation are $\leq 0.7$, discriminant validity is supported for all the domains.

Table 2 Construct validity and internal consistency of scores for patient satisfaction survey scale

\begin{tabular}{|l|l|l|l|l|}
\hline Questions & Cronbach's $\alpha$ & $\begin{array}{l}\text { Interitem } \\
\text { correlation }\end{array}$ & $\begin{array}{l}\text { Interitem } \\
\text { correlation } \\
\text { significance } \\
\text { value }\end{array}$ & $\begin{array}{l}\text { Scale-scale } \\
\text { discriminant validity }\end{array}$ \\
\hline Items (1-6) appointment and secretarial assistance & 0.93 & $0.62-0.78$ & $<0.001$ & $0.41-0.65$ \\
\hline Items (9-16) assisting medical staff and facilities & 0.96 & $0.70-0.85$ & $<0.001$ & $0.42-0.70$ \\
\hline Items (17-26) treating physician (consultant) & 0.97 & $0.67-0.86$ & $<0.001$ & $0.40-0.70$ \\
\hline
\end{tabular}


Table 3 Factor analysis and loadings per item using varimax rotation

\begin{tabular}{|c|c|c|c|c|}
\hline Scales & $\begin{array}{l}\text { Bartlett's } \\
\text { sphericity }\end{array}$ & KMO & $\begin{array}{l}\text { Factor } \\
\text { loading }\end{array}$ & $\begin{array}{l}\text { Variance } \\
\text { explained (\%) }\end{array}$ \\
\hline \multicolumn{5}{|c|}{ Items related to your appointment and secretarial assistance } \\
\hline Ease of scheduling your appointment & \multirow[t]{6}{*}{$<0.001$} & \multirow[t]{6}{*}{0.902} & 0.702 & \multirow[t]{6}{*}{74.84} \\
\hline Courtesy & & & 0.761 & \\
\hline Efficiency & & & 0.758 & \\
\hline Communication skill & & & 0.779 & \\
\hline Availability of the physician & & & 0.702 & \\
\hline Overall satisfaction & & & 0.788 & \\
\hline \multicolumn{5}{|c|}{ Items related to the assisting medical staff and facilities } \\
\hline Thoroughness about case & \multirow[t]{8}{*}{$<0.001$} & \multirow[t]{8}{*}{0.943} & 0.765 & \multirow[t]{8}{*}{79.20} \\
\hline Courtesy & & & 0.847 & \\
\hline Efficiency & & & 0.815 & \\
\hline Communication skill & & & 0.784 & \\
\hline Clarity in explanation & & & 0.765 & \\
\hline Ability to resolve your queries & & & 0.797 & \\
\hline Privacy of consultation & & & 0.742 & \\
\hline Overall satisfaction & & & 0.821 & \\
\hline \multicolumn{5}{|c|}{ Items related to your treating physician (consultant) } \\
\hline Time spent & \multirow[t]{10}{*}{$<0.001$} & \multirow[t]{10}{*}{0.945} & 0.713 & \multirow[t]{10}{*}{80.01} \\
\hline Willingness to listen & & & 0.821 & \\
\hline Ability to explain & & & 0.823 & \\
\hline Explanation of tests & & & 0.805 & \\
\hline Your involvement & & & 0.741 & \\
\hline Ability to diagnose problems & & & 0.818 & \\
\hline Skill in treating condition & & & 0.798 & \\
\hline Responsiveness to questions & & & 0.817 & \\
\hline Gave comfort and support & & & 0.822 & \\
\hline Overall satisfaction & & & 0.857 & \\
\hline
\end{tabular}

Abbreviation: KMO, Kaiser-Meyer-Olkin.

\section{Factor Analysis}

The KMO values as well as Bartlett's test for Sphericity strongly support construct validity for most of the domains, as shown in - Table 3. Thus, after varimax rotation, items 1 to 6 appointment and secretarial assistance account for $74.84 \%$ of the variance; assisting medical staff and facilities account for $79.2 \%$ of the variance; and treating physician (consultant) accounts for $80.01 \%$ of the variance. However, the open-end items have KMO coefficient 0.492 ; hence, factor analysis for these questions was not valid.

\section{Internal Consistency}

For appointment and secretarial assistance domain, the Cronbach's $\alpha$ was calculated as 0.93 , Cronbach's $\alpha$ was 0.96 for assisting medical staff and facilities, and 0.97 for treating physician (consultant) domain. The overall reliability for the 25 items was 0.974 , as shown in - Table 2.

\section{Patients' Satisfaction}

There were a total 246 (72.6\% [95\% CI: 68-77\%]) patients out of 339 patients, who were estimated to be satisfied. The mean overall satisfaction score of the patient was 88.35 with standard deviation (SD) of 19.63. Patients were satisfied in most of the aspect of OPD consultation process including appointment scheduling process with a mean score (SD) of 86.87 (22.78), assistant medical staff and faculty with a mean score (SD) of 88.79 (20.79), and treating physician with a mean score (SD) of 90.19 (19.37); however, some expressed dissatisfaction toward the long-waiting times with a mean score (SD) of 67.48 (33.1), as shown in - Tables 4, 5, 6.

\section{Discussion}

The main objective of this survey study was to perform linguistic validation of the PSS questionnaire in a larger 
Table 4 The mean satisfaction scores of patients with items related to your appointment and secretarial assistance

\begin{tabular}{|l|l|}
\hline $\begin{array}{l}\text { Items related to your appointment } \\
\text { and secretarial assistance }\end{array}$ & $\begin{array}{l}\text { Mean (SD) patients } \\
\text { satisfaction score }\end{array}$ \\
\hline Ease of scheduling appointment & $83.11(25.45)$ \\
\hline Courtesy & $85.69(23.51)$ \\
\hline Efficiency & $87.09(23.89)$ \\
\hline Communication skill & $86.50(23.09)$ \\
\hline Availability of the physician & $87.39(23.19)$ \\
\hline Overall satisfaction & $86.87(22.78)$ \\
\hline
\end{tabular}

Abbreviation: SD, standard deviation.

Table 5 The mean satisfaction scores of patients with items related to the assisting medical staff and facilities

\begin{tabular}{|l|l|}
\hline $\begin{array}{l}\text { Items related to the assisting } \\
\text { medical staff and facilities }\end{array}$ & $\begin{array}{l}\text { Mean (SD) patients } \\
\text { satisfaction score }\end{array}$ \\
\hline Waiting time & $67.48(33.01)$ \\
\hline Thoroughness about case & $88.35(20.46)$ \\
\hline Courtesy & $87.68(20.83)$ \\
\hline Efficiency & $88.50(20.99)$ \\
\hline Communication skill & $87.32(23.35)$ \\
\hline Clarity in explanation & $88.57(21.25)$ \\
\hline Ability to resolve your queries & $87.68(22.21)$ \\
\hline Privacy of consultation & $89.75(20.71)$ \\
\hline Overall satisfaction & $88.79(20.79)$ \\
\hline
\end{tabular}

Abbreviation: SD, standard deviation.

cohort of Indian patients compared with the earlier pilot study. In our previous study, in 50 English-speaking patients, the PSS questionnaire supported convergent and discriminant validity and the overall reliability of the PSS was $0.96 .^{24}$ In our study, we included women from all over India with different linguistic and socioeconomic backgrounds to represent the true population visiting the daily OPDs. The likelihood of generalizability of the results if supported by the narrow $\mathrm{CI}$ (95\% CI: 68-77\%) of the proportion of satisfied patients as the $\mathrm{Cl}$ is $<10 \%$ that is acceptable in terms that the true population estimate will fall between these intervals. In this study, the PSS supported convergent and discriminant validity with the reliability of 0.96 and good internal consistency. Furthermore, scores on each domain of the questionnaire correlated significantly with an overall satisfaction score of the patients, suggesting that each question in domain measured some aspect of patient's satisfaction. It also revealed that the items chosen in each domain were related and hence resulted in good internal reliability. Moreover, there was a concurrence between the score of each domain with the overall satisfaction score, implying that all questions impacted patients' overall satisfaction.
Table 6 The mean satisfaction scores of patients with items related to your treating physician

\begin{tabular}{|l|l|}
\hline $\begin{array}{l}\text { Items related to your treating } \\
\text { physician }\end{array}$ & $\begin{array}{l}\text { Mean (SD) patients } \\
\text { satisfaction score }\end{array}$ \\
\hline Time spent & $85.77(22.47)$ \\
\hline Willingness to listen & $88.20(21.86)$ \\
\hline Ability to explain & $88.72(22.09)$ \\
\hline Explanation of tests & $88.86(20.97)$ \\
\hline Your involvement & $88.13(21.26)$ \\
\hline Ability to diagnose problems & $90.78(19.56)$ \\
\hline Skill in treating a condition & $90.86(19.07)$ \\
\hline Responsiveness to questions & $88.72(20.71)$ \\
\hline Gave comfort and support & $89.68(20.18)$ \\
\hline Overall satisfaction & $90.19(19.37)$ \\
\hline Overall satisfaction & $88.35(19.63)$ \\
\hline
\end{tabular}

Abbreviation: SD, standard deviation.

The EORTC IN-PATSAT32 is a multidimensional scale specifically designed to assess the satisfaction of care services by patients in oncology setups and was validated in the context of a large multicentric study in 2004. The EORTC INPATSAT 32 that has been validated in different populations has shown strong psychometric properties. ${ }^{28}$ The PMH-PSQMD is validated for outpatients with Cronbach's $\alpha$ value of $0.97 .^{29}$ The most commonly used tool worldwide is EORTC OUTPATSAT $35^{18}$ and EORTC INPATSAT32. ${ }^{17}$ However, these questionnaires are not validated in the Indian population, and our questionnaire is a novel one in this regard. At the time when the pilot study with PSS was undertaken, the EORTC OUTPATSAT 35 questionnaire was not validated in Indian patients. Hence, the PSS tool was formed to suit the local clinical environment. Moreover, it is now known that the EORTC has revised the OUTPATSAT 35 questionnaire and made a new one EORTC PATSAT 33 core questionnaire and EORTC OUTPAT 7 for the outpatient setting. ${ }^{18}$ It comprises of seven questions related to medical professionals, waiting time, and information provided by caregivers. This questionnaire is yet to undergo cross-cultural validation including India.

PSS questionnaire is unique from other tools in various aspects. It has items separately for care provided by resident doctors that no other tools have assessed so far. It has included all the items about a patient's visit in an OPD from the appointment process to decision-making, giving it a holistic value. The items for physicians, nurses, and secretary have been segregated. The majority of the tools are too lengthy (32-60 items), and this restricts its practical use in a busy outpatient clinic. Hence, we developed this questionnaire that is an abbreviated 28 item tool, which will facilitate its use in the clinical practice to evaluate the quality of service.

The present findings support that PSS tool is highly reliable and valid and suitable for use in the Indian population in the outpatient clinic. Patients have certain 
expectations from the health-care provider, and their satisfaction or dissatisfaction is an outcome of their experience. ${ }^{3}$ Patients' perception of care is also a reflection of the doctorpatient relationship. Psychologists say that satisfied patients tend to follow medical advice with diligence as they trust their physician. ${ }^{8}$ Patient satisfaction should be given due importance and efforts must be taken to evaluate and improve it. This PSS tool can be used to assess the satisfaction levels of patients routinely and can guide us to provide patients their unmet needs. It will also be worthwhile to assess the satisfaction levels longitudinally at multiple time points as this will give an opportunity to test-retest the psychometric properties of the PSS questionnaire to study consistency in its performance. This we intend to undertake in the future wherein we would evaluate the satisfaction of the patients at three time points over their treatment course, as we expect that their needs will differ in different phases. Nonetheless, the PSS questionnaire has turned out to be a robust tool which can be considered for routine use and which can also serve as a measure of performance indicator. This tool can be used in other nononcological outpatient clinics as well.

\section{Conclusion}

The PSS tool has shown high reliability and validity when tested in the larger cohort of breast cancer patients and can be used in routine clinical practice. The robustness of the tool suggests its potential for wider dissemination across the country in nononcological outpatient clinics as well. Further studies can be considered to evaluate the temporal trends in patient satisfaction over the course of their treatment.

\section{Ethics}

This study was approved by the Tata Memorial Centre Ethics Committee on March 22, 2017 and project number 1835 was assigned. Patients were given consent forms in their preferred language and written consent was obtained. The procedures followed were in accordance with the ethical standards of the institutional committee on human experimentation and with the Helsinki Declaration of 1964, as revised in 2013.

\section{Funding}

None.

\section{Conflict of Interest \\ None declared.}

\section{References}

1 Pascoe GC. Patient satisfaction in primary health care: a literature review and analysis. Eval Program Plann 1983;6(3-4):185-210

2 Xesfingi S, Vozikis A. Patient satisfaction with the healthcare system: Assessing the impact of socio-economic and healthcare provision factors. BMC Health Serv Res 2016;16:94

3 Sitzia J, Wood N. Patient satisfaction: a review of issues and concepts. Soc Sci Med 1997;45(12):1829-1843
4 Junewicz A, Youngner SJ. Patient-satisfaction surveys on a scale of 0 to 10: improving health care, or leading it astray? Hastings Cent Rep 2015;45(03):43-51

5 Mahapatra S, Nayak S, Pati S. Quality of care in cancer: an exploration of patient perspectives. J Family Med Prim Care 2016;5(02):338-342

6 Ware JE Jr, Davies-Avery A, Stewart AL. The measurement and meaning of patient satisfaction. Health Med Care Serv Rev 1978;1 (01):1, 3-15

7 Brédart A, Razavi D, Delvaux N, Goodman V, Farvacques C, Van Heer C. A comprehensive assessment of satisfaction with care for cancer patients. Support Care Cancer 1998;6(06):518-523

8 Hardy GE, West MA, Hill F. Components and predictors of patient satisfaction. Br J Health Psychol 1996;1:65-85

9 Nguyen TV, Bosset JF, Monnier A, et al. Determinants of patient satisfaction in ambulatory oncology: a cross sectional study based on the OUT-PATSAT35 questionnaire. BMC Cancer 2011;11:526

10 Lis CG, Rodeghier M, Gupta D. Distribution and determinants of patient satisfaction in oncology: a review of the literature. Patient Prefer Adherence 2009;3:287-304

11 Naidu A. Factors affecting patient satisfaction and healthcare quality. Int J Health Care Qual Assur 2009;22(04):366-381

12 Bergenmar M, Nylén U, Lidbrink E, Bergh J, Brandberg Y. Improvements in patient satisfaction at an outpatient clinic for patients with breast cancer. Acta Oncol 2006;45(05):550-558

13 Patient Satisfaction. n.d. Accessed July 6, 2021 from: https://en. wikipedia.org/wiki/Patient_satisfaction

14 Heath S. Patient Satisfaction and HCAHPS: What It Means for Providers n.d. Accessed July 6, 2021 from: https:// patientengagementhit.com/features/patient-satisfaction-andhcahps-what-it-means-for-providers

15 Pascoe GC. Patient satisfaction in primary health care: a literature review and analysis. Eval Program Plann 1983;6(3-4):185-210. Doi: 10.1016/0149-7189(83)90002-2

16 Cleary PD. The increasing importance of patient surveys. Now that sound methods exist, patient surveys can facilitate improvement. BMJ 1999;319(7212):720-721

17 EORTC INPAT SAT 35 n.d. Accessed July 6, 2021 from: https:// www.eortc.org/app/uploads/sites/2/2018/08/Specimen-IN-PATSAT32-English.pdf

18 EORTC PAT SAT 33 n.d. https://qol.eortc.org/questionnaire/qlqpatsat-c33/. Accessed July 6, 2021

19 Kleeberg UR, Feyer P, Günther W, Behrens M. Patient satisfaction in outpatient cancer care: a prospective survey using The PASQOC questionnaire. Support Care Cancer 2008;16(08):947-954

20 Ware JE, Snyder MK, Wright W. Long form Patient Satisfaction Questionnaire (PSQ-III). 1976. Accessed July 6, 2021 from: https:// www.rand.org/content/dam/rand/www/external/health/surveys_ tools/psq/psq3_survey.pdf

21 Loblaw DA, Bezjak A, Bunston T. Development and testing of a visit-specific patient satisfaction questionnaire: the Princess Margaret Hospital Satisfaction With Doctor Questionnaire. J Clin Oncol 1999;17(06):1931-1938

22 Sahu U. Major Differences between Healthcare in the US and India. 2016. Accessed July 6, 2021 from: https://www. huffingtonpost.in/utkarsh-sahu/a-tale-of-two-nations-ind_b_ 9261892.html

23 Niranjan. Major Differences in Healthcare between the USA and India; June. 2018. Accessed July 6, 2021 from: https:// ehealthclinics.in/major-differences-in-healthcare-between-theusa-and-india/

24 Shirley Lewis, Tabassum Wadasadawala, Pallavi Rane, Sudeep Gupta, Santam Chakraborty, et al. (2017) Validation of Patient Satisfaction Survey (PSS) for Outpatient Care Carried out in MultiDisciplinary Breast Clinic. BAOJ Cancer Res Ther03:035

25 Campbell DT, Fiske DW. Convergent and discriminant validation by the multitrait-multimethod matrix. Psychol Bull 1959;56(02): 81-105 
26 Kaiser HF. An index of factorial simplicity. Psychometrika 1974; 39:31-36

27 Bartlett MS. Properties of sufficiency and statistical test. J Chem Inf Model 2013;53:1689-1699

28 Brédart A, Mignot V, Rousseau A, et al. Validation of the EORTC QLQ-SAT32 cancer inpatient satisfaction questionnaire by self- versus interview-assessment comparison. Patient Educ Couns 2004;54(02):207-212

29 Lis CG, Rodeghier M, Gupta D. Distribution and determinants of patient satisfaction in oncology: A review of the literature. Patient Prefer Adherence 2009 Nov 3;03:287-304. Doi: 10.2147/ppa. s6351 